\title{
ANALISIS KESUKSESAN USAHA FOTOCOPY DI LINGKUNGAN UNIVERSITAS VETERAN BANGUN NUSANTARA SUKOHARJO DAN UNIVERSITAS MUHAMMADIYAH SURAKARTA
}

\author{
Roman Hetrianto ${ }^{1}$, Mathilda Sri Lestari ${ }^{2}$, Suprapto $^{3}$ \\ ${ }^{1}$ Mahasiswa Program Studi Teknik Industri Univet Bantara Sukoharjo \\ ${ }^{2,3}$ Staf Pengajar Program studi Teknik Industri Univet Bantara Sukoharjo \\ rromanhetri92@gmail.com, ${ }^{2}$ mathildasrilestari@yahoo.com, ${ }^{3}$ supraptodd@yahoo.co.id
}

\begin{abstract}
ABSTRAK
Usaha fotocopy merupakan salah satu usaha dengan persaingan yang sangat pesat. Usaha fotocopy banyak kita temui dilingkungan pendidikan (sekolah atau kampus) dan lingkungan perkantoran. Semakin banyaknya usaha fotocopy yang tersedia semakin banyak pula pilihan bagi konsumen untuk menentukan mana usaha fotocopy yang sesuai dengan apa yang mereka butuhkan. dan menyediakan pelayanan yang lengkap dan bagus. Sehingga usaha fotocopy dilingkungan kampus selalu dituntun untuk melakukan inovasi sebagai akibat dari kebutuhan pangsa pasar yang dinamis. Objek penelitian ini adalah usaha fotocopy yang terdapat pada lingkungan kampus Universitas Veteran Bangun Nusantara Sukoharjo dan Unieversitas Muhammadiyah Surakarta. Penelitian yang dilakukan adalah unutk menentukan faktor-faktor kesuksesan pada usaha fotocopy. Langkah yang dilakukan meliputi penentuan usaha Fotocopy di lingkungan kampus Universitas Veteran Bangun Nusantara Sukoharjo dan Unieversitas Muhammadiyah Surakarta, menentukan indikator kesuksesan, survei market share, menentukan usaha Fotocopy yang akan diteliti berdasarkan diagram pareto, menentukan karakter usaha sukses berdasarkan analisis atribut produk dan analisis konsumen, pemetaan pada kanvas strategi, uji korelasi dan menarik kesimpulan. Berdasarkan kanvas strategi, usaha Fotocopy di lingkungan kampus Univet Bantara yang paling sukses adalah usaha Fotocopy H.1. Faktor penyebab kesuksesannya adalah faktor pelayanan, kualitas fotocopy, kualitas jilid hard cover, kualitas jilid lakban, faktor fasilitas, luas toko, pencahayaan, lay-out dan faktor jam buka. Sedangkan usaha Fotocopy di lingkungan kampus UMS yang paling sukses adalah usaha Fotocopy E.2, penyebab kesuksesannya adalah faktor harga fotocopy HVS.
\end{abstract}

Kata kunci: market share, diagram pareto, kanvas strategi, uji korelasi.

\section{PENDAHULUAN}

Usaha merupakan kegiatan individu yang terorganisasi untuk menghasilkan dan menjual barang dan jasa guna mendapatkan keuntungan dalam memenuhi kebutuhan masyarakat (Hughes dan Kapoor, dalam Alma 2005). Dunia usaha sekarang berkembang sangat pesat, banyak usaha-usaha yang didirikan dilingkungan perkotaan, pedesaan, lingkungan perkantoran dan juga lingkungan pendidikan seperti lingkungan kampus misalnya. Lokasi untuk mendirikan sebuah usaha juga pasti akan menyesuaikan dengan bidang usaha tersebut, seperti pelayanan apa yang akan diberikan oleh usaha tersebut, untuk siapa pelayanan tersebut tepat diberikan. Seiring pesatnya perkembangan dunia usaha, para pelaku usaha (wirausaha) juga pasti akan menciptakan ide-ide untuk memberikan pelayanan yang terbaik dengan tujuan menarik perhatian konsumen.

Usaha fotocopy merupakan salah satu usaha dengan persaingan yang sangat pesat. Usaha fotocopy banyak kita temui dilingkungan pendidikan (sekolah atau kampus) dan lingkungan perkantoran. Usaha fotocopy dilingkungan pendidikan dan lingkungan perkantoran akan selalu dituntut untuk melakukan pelayanan yang sesuai dengan keinginan konsumen. 
Universitas Veteran Bangun Nusantara Sukoharjo (Univet Bantara Sukoharjo) adalah universitas yang berada di Kabupaten Sukoharjo, dengan jumlah mahasiswa sebanyak 7500 orang. Hal tersebut merupakan salah satu faktor dimana dilingkungan Univet Bantara Sukoharjo banyak terdapat usaha fotocopy. Jasa yang ditawarkan usaha fotocopy sesuai dengan apa yang dibutuhkan mahasiswa, secara umum jasa yang ditawarkan adalah fotocopy itu sendiri, jilid buku, laminating, print, cetak foto, scan, menjual alat tulis kantor (ATK), dan adapula usaha fotocopy yang menyediakan jasa pengetikan dan pengolahan data. Sekitar lokasi Univet Bantara Sukoharjo juga terdapat kantor Pemerintah Kabupaten Sukoharjo, beberapa sekolah tingkat SMA, kantor Pengadilan Negeri. Sehingga usaha fotocopy dilingkungan Univet Bantara Sukoharjo ini selalu ramai setiap harinya. Universitas Muhammadiyah Surakarta (UMS) adalah universitas yang terletak di Surakarta dengan jumlah mahasiswa sebanyak 12000 orang. Sama halnya seperti dilingkungan Univet Bantara Sukoharjo, di lingkungan UMS ini juga terdapat banyak usaha fotocopy dengan berbagai macam pelayanan yang dibutuhkan oleh mahasiswa.

Semakin banyaknya usaha fotocopy yang tersedia semakin banyak pula pilihan bagi konsumen untuk menentukan mana usaha fotocopy yang sesuai dengan apa yang mereka butuhkan. dan menyediakan pelayanan yang lengkap dan bagus. Sehingga usaha fotocopy dilingkungan kampus selalu dituntun untuk melakukan inovasi sebagai akibat dari kebutuhan pangsa pasar yang dinamis. Berdasarkan latar belakang diatas maka penelitian ini akan meneliti tentang analisis kesuksesan usaha fotocopy dilingkungan kampus Univet Bantara Sukoharjo dan UMS. Tujuan dari analisis kesuksesan usaha fotocopy ini adalah dapat mengetahui bagaimana usaha fotocopy dengan pelayanan yang sesuai dengan kebutuhan konsumen.

Penelitian terdahulu tentang analisis kesuksesan juga pernah dilakukan oleh beberapa peneliti. Haryoko (2008) melakukan penelitian tentang produk sukses handphone. Dalam penelitiannya ditemukan faktor sukses handphone diantaranya adalah karakter desain yang simple dan menarik yang didukung dengan kombinasi warna produk, kualitas layar yang halus dan tajam, harga produk dan harga perlengkapan yang relatif rendah, tingkat kemudahan penggunaan yang cukup baik, dan tingkat ergonomi produk yang tinggi.

Istiqlaliyah (2009) menganalisa persaingan pada handphone high end beserta perhitungan model karakteristik kesuksesan. Karakter yang membedakan handphone high end dengan kelas lain adalah performa, desain, portabilitas, serta brand value yang tinggi berdasarkan konsumen.

Pramudi (2010) melakukan riset mengenai produk-produk sukses berbasis teknologi kategori me-too. Produk yang diambil adalah produk peramban dan handphone. Hasil penelitian menunjukkan bahwa produk peramban yang muncul sebagai produk sukses adalah Mozilla Firefox dan produk handphone yang muncul sebagai produk sukses adalah Beyond B9000. Karakteristik kesuksesan antar me-too produk terdapat pada brand value dengan tingkat kepercayaan sebesar $90 \%$ berdasarkan hasil uji korelasi.

Mathilda (2011) meneliti mengenai analisis kesuksesan produk minuman suplemen. Faktor-faktor yang membedakan pada produk minuman suplemen adalah estetika kemasan, khasiat, rasa, perbandingan additive ingredients, petunjuk, varian rasa, harga, dan tahun peluncuran produk.

\section{METODE PENELITIAN}

Objek dalam penelitian ini adalah usaha fotocopy yang terdapat di lingkungan Universitas Veteran Bangun Nusantara Sukoharjo dan Universitas Muhammadiyah Surakarta. Sejumlah 8 usaha fotocopy terdapat di kampus Universitas Veteran Bangun Nusantara Sukoharjo dan sejumlah 16 usaha foto copy terdapat di kampus Universitas 
Muhammadiyah Surakarta. Berikut produk dan pelayanan yang disediakan dari hasil observasi pada usaha fotocopy dilingkungan kampus Univet Bantara Sukoharjo dan UMS.

Tabel 1. Daftar Produk Usaha Fotocopy di Sekitar Kampus Univet Bantara

\begin{tabular}{|c|c|c|}
\hline No. & Nama Usaha & Produk \\
\hline 1. & Fotocopy A.1 & $\begin{array}{l}\text { 1. Fotocopy (HVS, kwarto, folio, A3, buram) } \\
\text { 2. Jilid (hard cover/skripsi, soft cover, biasa) } \\
\text { 3. Press } \\
\text { 4. Laminating } \\
\text { 5. Print }\end{array}$ \\
\hline 2. & Fotocopy B.1 & $\begin{array}{l}\text { 1. Fotocopy (HVS, kwarto, buram, perbesar \& perkecil, } \\
\text { transparansi) } \\
\text { 2. Jilid (skripsi, makalah, laporan, tugas) } \\
\text { 3. Pengetikan } \\
\text { 4. Laminating dan press }\end{array}$ \\
\hline 3. & Fotocopy C.1 & $\begin{array}{l}\text { 1. Fotocopy } \\
\text { 2. Laser print } \\
\text { 3. Print } \\
\text { 4. Cetak foto } \\
\text { 5. Scan } \\
\text { 6. Jilid (hard cover, soft cover, mika, dll.) } \\
\text { 7. Service laptop }\end{array}$ \\
\hline 4. & Fotocopy D.1 & $\begin{array}{l}\text { 1. Pengetikan } \\
\text { 2. Print warna } \\
\text { 3. Edit skripsi } \\
\text { 4. Olah data } \\
\text { 5. Fotocopy } \\
\text { 6. Jilid skripsi } \\
\text { 7. Press dan laminating } \\
\text { 8. Alat Tulis Kantor (ATK) }\end{array}$ \\
\hline 5. & Fotocopy E.1 & $\begin{array}{l}\text { 1. Print (warna, leser) } \\
\text { 2. Fotocopy (HVS dan buram) } \\
\text { 3. Laminating } \\
\text { 4. Jilid (spiral, mika, soft cover, hard cover) } \\
\text { 5. Alat-alat kantor } \\
\text { 6. Pengetikan dan olah data }\end{array}$ \\
\hline 6. & Fotocopy F.1 & $\begin{array}{l}\text { 1. Fotocopy } \\
\text { 2. Alat Tulis Kantor (ATK) }\end{array}$ \\
\hline 7. & Fotocopy G.1 & $\begin{array}{l}\text { 1. Fotocopy (HVS-buram) } \\
\text { 2. Jilid (lakban, soft cover, bendel majalah, dll.) }\end{array}$ \\
\hline 8. & Fotocopy H.1 & $\begin{array}{l}\text { 1. Fotocopy (HVS dan buram) } \\
\text { 2. Jilid (skripsi, spiral, soft cover, bendel majalah, press tepi) } \\
\text { 3. Laminating } \\
\text { 4. Print (warna, leser) } \\
\text { 5. Alat-alat kantor }\end{array}$ \\
\hline
\end{tabular}

Pada Tabel 1 dapat dilihat hasil observasi lapangan lingkungan kampus Univet Bantara yaitu terdapat 8 usaha fotocopy dengan bermacam-macam produk dan pelayanan. 
Tabel 2. Daftar Produk Usaha Fotocopy di Sekitar Kampus UMS

\begin{tabular}{|c|c|c|}
\hline No. & Nama Usaha & Produk \\
\hline 1. & Fotocopy A.2 & $\begin{array}{l}\text { 1. Fotocopy } \\
\text { 2. Print (hitam putih dan warna) } \\
\text { 3. Jilid } \\
\text { 4. Scan } \\
\text { 5. Cetak Foto } \\
\text { 6. Burning CD/VCD } \\
\text { 7. Laminating/press }\end{array}$ \\
\hline 2. & Fotocopy B.2 & $\begin{array}{l}\text { 1. Fotocopy dan print (A3, HVS 60-70 gr, A4 70-80-100 gr, } \\
\text { HVS warna 60-70 gr, transparan/OHP, buram) } \\
\text { 2. Press dan laminating (ijazah, ktp, foto, laminating ukuran } \\
\text { A3) } \\
\text { 3. Jilid (cover warna, hard cover (skripsi/tesis), soft cover, } \\
\text { langsung/buku, cover mika, spiral kawat, plastik, porto } \\
\text { folio) }\end{array}$ \\
\hline 3. & Fotocopy C.2 & $\begin{array}{l}\text { 1. Fotocopy } \\
\text { 2. Press } \\
\text { 3. Jilid } \\
\text { 4. Laminating } \\
\text { 5. Jilid hard cover/skripsi } \\
\text { 6. Scanning }\end{array}$ \\
\hline 4. & Fotocopy D.2 & $\begin{array}{l}\text { 1. Fotocopy (kwarto A4 70-80 gr, folio F4 60-70 gr, A3, } \\
\text { transparan/OHP } \\
\text { 2. Jilid (hard cover/skripsi, soft cover, buku, spiral/ring, } \\
\text { mika-manila) } \\
\text { 3. Press dan laminating (dokumen penting, ijazah, ktp) }\end{array}$ \\
\hline 5. & Fotocopy E.2 & $\begin{array}{l}\text { 1. Fotocopy (A3, HVS } 60-70 \text { gr, A4 70-80-100 gr, HVS } \\
\text { warna } 60-70 \text { gr, transparan/OHP, buram) } \\
\text { 2. Print } \\
\text { 3. Laminating/press } \\
\text { 4. Jilid soft cover } \\
\text { 5. Jilid hard cover/skripsi }\end{array}$ \\
\hline 6. & Fotocopy F.2 & $\begin{array}{l}\text { 1. Fotocopy (HVS, buram, kwarto) } \\
\text { 2. Press } \\
\text { 3. Laminating } \\
\text { 4. Print } \\
\text { 5. Alat-alat tulis }\end{array}$ \\
\hline 7. & Fotocopy G.2 & $\begin{array}{l}\text { 1. Fotocopy } \\
\text { 2. Laminating } \\
\text { 3. Jilid cover } \\
\text { 4. Jilid spiral plastik } \\
\text { 5. Alat Tulis Kantor (ATK) }\end{array}$ \\
\hline 8. & Fotocopy H.2 & $\begin{array}{l}\text { 1. Fotocopy (HVS-buram) } \\
\text { 2. Jilid } \\
\text { 3. Print dan olah data } \\
\text { 4. Alat-alat tulis }\end{array}$ \\
\hline
\end{tabular}


Tabel 2. Daftar Produk Usaha Fotocopy di Sekitar Kampus UMS (lanjutan)

\begin{tabular}{|c|l|l|}
\hline No. & \multicolumn{1}{|c|}{ No. } & \multicolumn{1}{c|}{ Produk } \\
\hline 9. & Fotocopy I.2 & 1. Fotocopy \\
& & 2. Jilid (cover warna, soft cover, hard cover/skripsi) \\
& & 3. Print \\
& & 4. Cetak foto \\
5. Pengetikan
\end{tabular}

Pada Tabel 2 dapat dilihat hasil observasi lapangan lingkungan kampus Univet Bantara yaitu terdapat 8 usaha fotocopy dengan bermacam-macam produk dan pelayanan.

\section{Tahap Penelitian}

Berdasarkan Diagram Alir pada Gambar 1, maka akan dijelaskan tahapan-tahapan penelitian. 
Langkah 1 : Menentukan objek penelitian. Objek pada penelitian ini ada usaha foto copy yang terletak di lingkungan kampus Univet Bantara Sukoharjo dan UMS dengan jarak terdekat dengan kampus \pm 120 meter dan jarak terjauh \pm 200 meter, dengan rata-rata jarak antara usaha fotocopy satu dengan yang lainnya adalah 29 meter.

Langkah 2 :Menentukan Indikator Kesuksesan. Indikator tingkat kesuksesan pada penelitian ini diketahui dengan menghitung banyaknya penjualan kertas dalam satuan lembaran. Untuk menghitung indikator kesuksesan tersebut digunakan persamaan untuk Market Share $=($ Jumlah Penjualan Perusahaan) / (Jumlah penjualan industri). Market share adalah jumlah produk yang diminta oleh pasar, jumlah penjualan perusahaan adalah jumlah penjualan perusahaan dalam waktu tertentu, dan jumlah penjualan industri adalah Jumlah penjualan Industri dalam waktu tertentu.

Langkah 3 : Menentukan Objek Penelitian menggunakan Diagram Pareto. Prinsip Pareto menunjukan bahwa 20\% penyebab diakibatkan oleh $80 \%$ akibat. Prinsip Pareto diterapkan dengan diagram pareto dengan klasifikasinya diurutkan dari kiri ke kanan. Contoh Diagram Pareto adalah sebagai berikut :

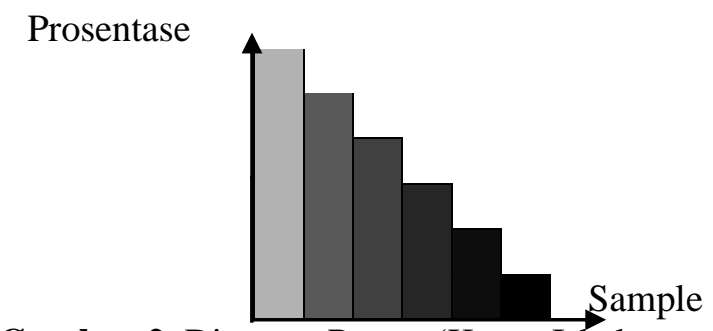

Gambar 2. Diagram Pareto (Kaoru Ishakawa, 1989)

Langkah 4 : Menentukan Karakter Usaha Sukses Berdasarkan Atribut Produk. Data analisis atribut produk didapatkan melalui data primer. Data primer yang didapatkan berupa harga Fotocopy HVS dan jam buka. Dari data aktual yang telah didapat, kemudian dilakukan pemberian skor untuk masing-masing usaha Fotocopy. Selanjutnya dilakukan pembagian kategori dan perangkingan terhadap masing-masing usaha Fotocopy sesuai dengan tinggi rendahnya skor.

Langkah 5 : Menentukan Karakter Usaha Sukses Berdasarkan Analisis Konsumen. Analisis konsumen yang diteliti meliputi pelayanan, kualitas, dan fasilitas. Langkah-langkah analisis persepsi konsumen. Setelah semua data persepsi konsumen diperoleh kemudian diberi skor pembanding kepada masing-masing usaha Fotocopy lalu dilakukan pengelompokan berdasarkan faktor-faktor yang ada dan diberikan perangkingan terhadap tinggi rendahnya skor.

Langkah 6 : Kanvas Strategi. Kanvas strategi merupakan sebuah kerangka kerja analitis yang penting bagi inovasi nilai dan penciptaan samudra biru, penciptaan ruang pasar yang belum ada pesaingnya dan tanpa kompetisi (Kim dan Mauborgne, 2006). Pada penelitian ini kanvas strategi yang digunakan untuk menggambarkan faktor-faktor penyebab kesuksesan usaha sehingga dapat dibandingkan antar faktor yang ada terhadap masing-masing usaha dan akhirnya dapat diketahui faktor mana yang menyebabkan suatu usaha dapat mencapai kesuksesan.

\section{HASIL DAN PEMBAHASAN}

\section{Penentuan Produk Sukses}

Berdasarkan data penjualan kertas dalam satuan lembar (market share) pada tabel 3 dan tabel 4 dapat dibuat diagram pareto untuk mengetahui usaha Fotocopy di lingkungan kampus 
Univet Bantara dan UMS yang dapat dikategorikan sebagai usaha sukses. Usaha Fotocopy di lingkungan kampus Univet Bantara dan UMS yang sukses adalah yang masuk dalam $80 \%$ market share yang selanjutnya akan digunakan dalam obyek penelitian. Untuk usaha Fotocopy di lingkungan kampus Univet Bantara dan UMS yang tidak masuk dalam 80\% market share tidak akan dievalusai karena jumlah market sharenya sedikit, yaitu kurang dari $5 \%$.

Tabel 3. Data penjualan kertas rata-rata perhari Usaha Fotocopy di Lingkungan Kampus Univet Bantara

\begin{tabular}{|c|c|c|c|c|}
\hline No. & Usaha Fotocopy & Market Share (lembar) & Presentase & Kumulatif \\
\hline 1. & Fotocopy H.1 & 11500 & 31,85 & 31,85 \\
\hline 2. & Fotocopy A.1 & 9000 & 24,92 & 56,77 \\
\hline 3. & Fotocopy E.1 & 5000 & 13,85 & 70,62 \\
\hline 4. & Fotocopy C.1 & 3500 & 9,69 & 80,31 \\
\hline 5. & Fotocopy D.1 & 3010 & 8,34 & 88,65 \\
\hline 6. & Fotocopy B.1 & 2100 & 5,82 & 94,47 \\
\hline 7. & Fotocopy G.1 & 1500 & 4,15 & 98,62 \\
\hline 8. & Fotocopy F.1 & 500 & 1,38 & 100 \\
\hline & Total & 36110 & 100 & \\
\hline
\end{tabular}

Tabel 4. Data penjualan kertas rata-rata perhari Usaha Fotocopy di Lingkungan Kampus UMS

\begin{tabular}{|c|l|c|c|c|}
\hline No. & Usaha Fotocopy & Market Share (lembar) & Presentase & Kumulatif \\
\hline 1. & Fotocopy E.2 & 40617 & 36,28 & 36,28 \\
\hline 2. & Fotocopy K.2 & 30898 & 27,6 & 63,88 \\
\hline 3. & Fotocopy J.2 & 17885 & 15,97 & 79,85 \\
\hline 4. & Fotocopy A.2 & 3597 & 3,21 & 83,06 \\
\hline 5. & Fotocopy D.2 & 2645 & 2,36 & 85,42 \\
\hline 6. & Fotocopy B.2 & 2040 & 1,81 & 87,23 \\
\hline 7. & Fotocopy G.2 & 1740 & 1,56 & 88,79 \\
\hline 8. & Fotocopy P.2 & 1734 & 1,54 & 90,33 \\
\hline 9. & Fotocopy I.2 & 1705 & 1,52 & 91,85 \\
\hline 10. & Fotocopy N.2 & 1570 & 1,5 & 93,35 \\
\hline 11. & Fotocopy F.2 & 1550 & 1,37 & 94,72 \\
\hline 12. & Fotocopy H.2 & 1500 & 1,3 & 96,02 \\
\hline 13. & Fotocopy O.2 & 1250 & 1,11 & 97,13 \\
\hline 14. & Fotocopy M.2 & 1130 & 1 & 98,13 \\
\hline 15. & Fotocopy L.2 & 1060 & 0,97 & 99,1 \\
\hline 16. & Fotocopy C.2 & 1010 & 0,9 & 100 \\
\hline & Total & 111931 & 100 & \\
\hline
\end{tabular}

Tabel 5. Ringkasan korelasi indikator kesuksesan usaha Fotocopy di lingkungan kampus Univet Bantara.

\begin{tabular}{|l|c|l|c|c|c|}
\hline $\begin{array}{c}\text { Nama } \\
\text { Fotocopy }\end{array}$ & Parameter & \multicolumn{1}{|c|}{ Faktor yang dikaji } & $\begin{array}{c}\text { Nilai } \\
\text { Korelasi }\end{array}$ & $\begin{array}{c}\text { Nilai } \\
\text { signifikan }\end{array}$ & Keterangan \\
\hline & & Pelayanan & 0.881 & 0.119 & Berkorelasi \\
\cline { 3 - 6 } & Kualitas Fotocopy & 0.798 & 0.202 & Berkorelasi \\
\cline { 3 - 6 } 1. H.1 & \multirow{2}{*}{$\begin{array}{c}\text { Market } \\
\text { A.1 }\end{array}$} & $\begin{array}{l}\text { Kualitas jilid hard } \\
\text { cover }\end{array}$ & 0.578 & 0.422 & Berkorelasi \\
\cline { 3 - 6 } E. C.1 & share & Kualitas Jilid biasa & -0.119 & 0.881 & $\begin{array}{c}\text { Tidak } \\
\text { Berkorelasi }\end{array}$ \\
\hline
\end{tabular}


Tabel 5. Ringkasan korelasi indikator kesuksesan usaha Fotocopy di lingkungan kampus Univet Bantara (lanjutan)

\begin{tabular}{|c|c|c|c|c|c|}
\hline $\begin{array}{c}\text { Nama } \\
\text { Fotocopy }\end{array}$ & Parameter & Faktor yang dikaji & $\begin{array}{c}\text { Nilai } \\
\text { Korelasi }\end{array}$ & $\begin{array}{c}\text { Nilai } \\
\text { signifikan }\end{array}$ & Keterangan \\
\hline \multirow{7}{*}{$\begin{array}{ll}\text { 1. } & \text { H.1 } \\
\text { 2. } & \text { A.1 } \\
\text { 3. } & \text { E.1 } \\
\text { 4. } & \text { C. } 1\end{array}$} & \multirow{7}{*}{$\begin{array}{c}\text { Market } \\
\text { share }\end{array}$} & Fasilitas & 0.997 & 0.003 & Berkorelasi \\
\hline & & Luas Toko & 0.982 & 0.018 & Berkorelasi \\
\hline & & Pencahayaan & 0.946 & 0.054 & Berkorelasi \\
\hline & & Jumlah server & 0.678 & 0.322 & Berkorelasi \\
\hline & & Lay-out & 0.816 & 0.184 & Berkorelasi \\
\hline & & Harga Fotocopy & -0.319 & 0.681 & $\begin{array}{c}\text { Tidak } \\
\text { berkorelasi }\end{array}$ \\
\hline & & Jam buka & -0.41 & 0.59 & $\begin{array}{c}\text { Tidak } \\
\text { berkorelasi }\end{array}$ \\
\hline
\end{tabular}

Tabel 6. Ringkasan korelasi indikator kesuksesan usaha Fotocopy di lingkungan kampus

\begin{tabular}{|l|c|l|c|c|c|}
\hline \multicolumn{1}{|c|}{$\begin{array}{c}\text { Nama } \\
\text { Fotocopy }\end{array}$} & Parameter & \multicolumn{1}{|c|}{ Faktor yang dikaji } & $\begin{array}{c}\text { Nilai } \\
\text { Korelasi }\end{array}$ & $\begin{array}{c}\text { Nilai } \\
\text { signifikan }\end{array}$ & Keterangan \\
\hline \multirow{4}{*}{$\begin{array}{l}\text { 1. E.2 } \\
\text { K.2 } \\
\text { J.2 J.2 }\end{array}$} & Pelayanan & -0.405 & 0.735 & $\begin{array}{c}\text { Tidak } \\
\text { berkorelasi }\end{array}$ \\
\cline { 3 - 6 } & \multirow{4}{*}{$\begin{array}{c}\text { Market } \\
\text { share }\end{array}$} & Kualitas Fotocopy & 0.963 & 0.174 & Berkorelasi \\
\cline { 3 - 6 } & Kualitas jilid hard cover & -0.715 & 0.492 & $\begin{array}{c}\text { Tidak } \\
\text { berkorelasi }\end{array}$ \\
\cline { 3 - 6 } & Kualitas Jilid Biasa & 0.405 & 0.735 & $\begin{array}{c}\text { Tidak } \\
\text { berkorelasi }\end{array}$ \\
\cline { 3 - 6 } & Fasilitas & -0.57 & 0.614 & $\begin{array}{c}\text { Tidak } \\
\text { berkorelasi }\end{array}$ \\
\cline { 3 - 6 } & Luas Toko & 0.661 & 0.54 & Berkorelasi \\
\cline { 3 - 6 } & Pencahayaan & 0.083 & 0.947 & $\begin{array}{c}\text { Tidak } \\
\text { berkorelasi }\end{array}$ \\
\cline { 3 - 6 } & Jumlah server & 0.405 & 0.735 & $\begin{array}{c}\text { Tidak } \\
\text { berkorelasi }\end{array}$ \\
\cline { 3 - 6 } & & Lay-out & 0.997 & 0.053 & Berkorelasi \\
\cline { 3 - 6 } & Harga Fotocopy & -1 & 0.001 & $\begin{array}{c}\text { Tidak } \\
\text { berkorelasi }\end{array}$ \\
\cline { 3 - 6 } & & Jam buka & 0.821 & 0.386 & Berkorelasi \\
\hline
\end{tabular}

\section{Analisis Kesuksesan Produk Berdasarkan Kanvas Strategi}

Faktor-faktor penyebab kesuksesan usaha Fotocopy di lingkungan kampus Univet Bantara dan UMS yang dijadikan obyek penelitian meliputi faktor pelayanan, kualitas fotocopy, kualitas jilid hard cover, kualitas jilid lakban, fasilitas, luas toko, pencahayaan, jumlah server, lay-out, harga Fotocopy HVS, dan jam buka.

Analisis kesuksesan usaha Fotocopy di lingkungan kampus Univet Bantara dan UMS dilakukan dengan membandingkan faktor-faktor penyebab kesuksesan yang digambarkan dalam kanvas strategi. 
Tabel 7. Perbandingan Faktor-Faktor Penyebab Kesuksesan Usaha Fotocopy di Lingkungan Kampus Univet Bantara

\begin{tabular}{|l|l|l|l|l|}
\hline \multicolumn{1}{|c|}{ Faktor } & H.1 & A.1 & E.1 & C.1 \\
\hline Pelayanan & 1 & 0,992 & 0,98 & 0,998 \\
\hline Kualitas Fotocopy & 1 & 0,97 & 0,995 & 0,777 \\
\hline Kualitas Jilid Hard Cover & 1 & 0,992 & 0,972 & 0,992 \\
\hline Kualitas Jilid Lakban & 1 & 0,984 & 0,992 & 1 \\
\hline Fasilitas & 1 & 0,969 & 0,902 & 0,883 \\
\hline Luas Toko & 1 & 0,952 & 0,879 & 0,81 \\
\hline Pencahayaan & 1 & 0,992 & 0,948 & 0,968 \\
\hline Jumlah Server & 0,984 & 1 & 0,948 & 0,945 \\
\hline Lay-out & 1 & 0,984 & 0,976 & 0,895 \\
\hline Harga & 1 & 0,834 & 1 & 1 \\
\hline Jam Buka & 0,876 & 0,876 & 1 & 0,876 \\
\hline
\end{tabular}

\section{Analisis berdasarkan grafik kanvas strategi}

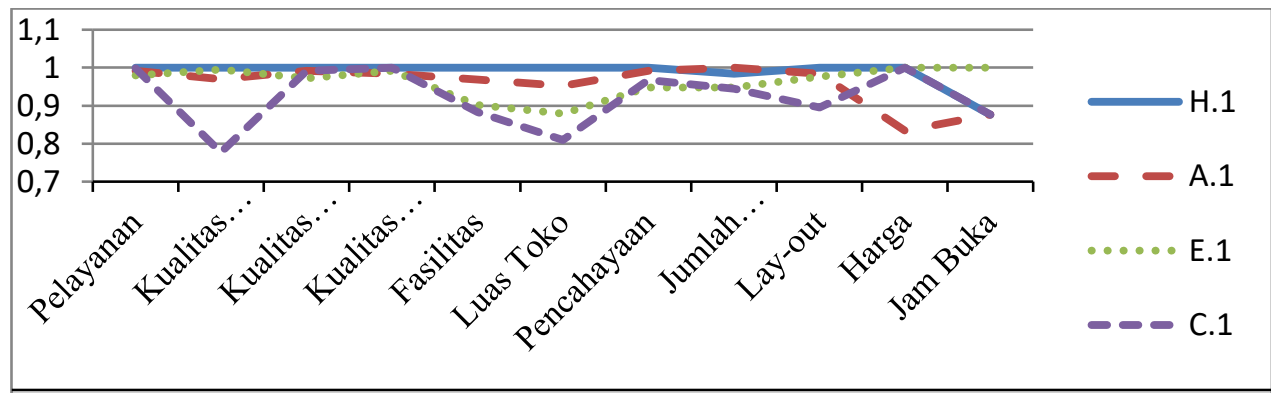

Gambar 3. Kanvas Strategi Faktor-Faktor Penyebab Kesuksesan Usaha Fotocopy di Lingkungan Kampus Univet Bantara

Usaha Fotocopy di lingkungan kampus Univet Bantara yang paling sukses berdasarkan market share Fotocopy H.1. Berdasarkan Gambar 3 dapat diketahui bahwa faktor penyebab kesuksesan usaha Fotocopy H.1 adalah faktor pelayanan, kualitas Fotocopy, kualitas jilid hard cover, kualitas jilid lakban, faktor fasilitas, luas toko, pencahayaan, lay-out dan faktor jam buka.

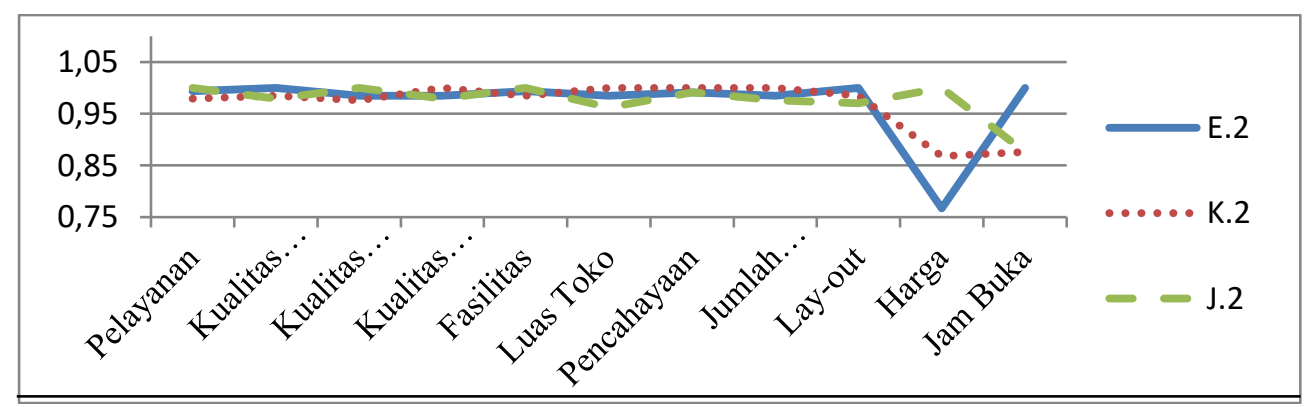

Gambar 4. Kanvas Strategi Faktor-Faktor Penyebab Kesuksesan Usaha Fotocopy di Lingkungan Kampus UMS

Sedangkan usaha Fotocopy di lingkungan kampus UMS yang paling sukses berdasarkan market share adalah Fotocopy E.2. Berdasarkan Gambar 4 menunjukkan bahwa faktor penyebab kesuksesan usaha Fotocopy E.2 adalah faktor harga, pada grafik menunjukkan garis harga tersebut lebih rendah dari harga usaha Fotocopy lain artinya harga Fotocopy lebih murah dari usaha Fotocopy lainnya yang ada di lingkungan kampus UMS. 


\section{KESIMPULAN}

\section{Kesimpulan}

Usaha Fotocopy yang paling sukses di lingkungan kampus Univet Bantara ialah usaha Fotocopy H.1, penyebab kesuksesan berdasarkan dari analisis persepsi konsumen yaitu faktor pelayanan, kualitas Fotocopy, kualitas jilid hard cover, kualitas jilid lakban, faktor fasilitas, faktor luas toko, faktor pencahayaan, faktor jumlah server, dan faktor lay-out. Sedangkan usaha Fotocopy yang paling sukses di lingkungan kampus UMS ialah usaha Fotocopy E.2, penyebab kesuksesannya terdapat pada analisis atribut produk yaitu pada segi harga Fotocopy HVS.

\section{Saran}

Penelitian ini nantinya juga dapat dijadikan referensi dalam melakukan penelitian lain khususnya tentang kesuksesan usaha Fotocopy dan dapat memberikan masukan pada setiap pengusaha Fotocopy khususnya dalam mengelola usahanya agar dapat memberikan pelayanan yang maksimal pada konsumen.

\section{DAFTAR PUSTAKA}

Alma, Buchari. 1889. Manajemen Pemasaran dan Pemasaran Jasa. Bandung: Alfabeta.

Haryoko, S. 2008. Analisis Karakteristik Kesuksesan Produk Handphone. Teknik Industri, Universitas Gadjah Mada. Yogyakarta.

Ishikawa, Kaoru. 1989. Teknik Penuntun Pengendalian Mutu. Jakarta: PT. Mediyatama Sarana Perkasa.

Istiqlaliyah, H. 2009. Karakter Produk Sukses Pada Produk Telepon Genggam Kelas High End. Program Studi Teknik Industri, Universitas Gadjah Mada. Yogyakarta.

Kim, Chan dan Renee Mauborgne. 2006. Strategi Samudra Biru (Blue Ocean Strategy). Jakarta: Serambi

Lestari, Mathilda S. 2011. Analisis Kesuksesan Produk Minuman Suplemen. Tesis, Program Studi Teknik Industri. Universitas Gadjah Mada. Yogyakarta.

Permana, Pramudi Ringga. 2010. Analisis Kesuksesan Produk-Produk Berbasis Teknologi

Kategori Me-Too. Program Studi Teknik Industri, Universitas Gadjah Mada. Yogyakarta. 